\title{
Perfil higiênico-sanitários durante a venda do camarão-da-Amazônia (Macrobrachium amazonicum) na cidade de Breves (Marajó, estado do Pará, Brasil)
}

\section{Hygienic-sanitary profile during the sale of the Amazon shrimp (Macrobrachium amazonicum) in the city of Breves (Marajó, Pará State - Brazil)}

Fabricio Nilo Lima da Silva*, Luã Caldas de Oliveira, Tiago Paixão Mangas, Andreza Soares dos Santos, Luciany do Socorro de Oliveira Sampaio, Antonia Rafaela Gonçalves Macedo \& Carlos Alberto Martins Cordeiro Instituto Federal de Educação, Ciência e Tecnologia do Pará - IFPA, Campus Breves

*E-mail: fabricio_nilo@hotmail.com

Recebido: 9 de fevereiro de 2017 / Aceito: 20 de abril de 2017: / Publicado: 8 de dezembro de 2017

Resumo objetivou-se traçar o perfil das condições higiênico-sanitárias durante a venda do Macrobrachium amazonicum na Feira Livre da cidade de Breves, estado do Pará. A pesquisa foi realizada no mês de setembro/2016 em cinco pontos de venda (Box). Foi aplicado um Check-list sobre as condições do setor: a) Infraestrutura e organização (existência de sanitários, água disponível, ambiente organizado e limpo, feirante visível e pessoa exclusiva para cobrar); b) Feirantes (uso de avental, proteção nos cabelos e luva descartável) e c) Camarão (existência de vitrine, oferta adequada, refrigeração, procedência/identificação e uso de utensílios adequados). Para cada observação positiva foi atribuído créditos às respostas: coluna " $\mathrm{A}$ " $=0,5 \mathrm{e}$ coluna "B" $=0,25$ e negativas $=0$. Foi observado, que apenas um ponto de venda apresentou a maior pontuação (1,75 créditos), enquanto que os demais, apresentaram as menores (0,75 e 1,25 créditos). Contudo, fica visível que em nenhuma das bancas de camarões-da-Amazônia visitada os valores obtidos se aproximam do valor máximo permitido de cada ponto de venda. Conclui-se, há uma necessidade de reestruturação da feira, bem como, promover projetos de extensão a capacitação e conscientização dos manipuladores a fim de que sejam passadas informações básicas a respeito das condições corretas de manipulação e comercialização de camarões de água doce.

Palavras-chave: crustáceo, consumo, saúde pública.

\begin{abstract}
The objective of this study was to outline the profile of the hygienic-sanitary conditions during the sale of the Macrobrachium amazonicum at the Free Trade Fair of the city of Breves, Pará State. The survey was conducted in September/2016 at five points of sale (Box). A checklist was applied on the conditions of the sector: a) Infrastructure and organization (existence of toilets, available water, organized and clean environment, visible market and exclusive person to collect); B) Markets (use of apron, hair protection and disposable gloves) and c) Shrimp (existence of showcase, adequate supply, refrigeration, provenance / identification and use of suitable utensils). For each positive observation, responses were attributed: column " $\mathrm{A} "=0.5$ and column "B" $=0.25$ and negative $=0$. It was observed that only one point of sale had the highest score ( 1.75 credits), while the others had the lowest ( 0.75 and 1.25 credits). However, it is clear that in none of the Amazon shrimp stands visited do the values obtained approximate the maximum allowed value of each point of sale. In conclusion, there is a need to restructure the fair, as well as to promote extension projects to training and awareness of the manipulators so that basic information about the correct conditions of handling and marketing of freshwater prawns is given.
\end{abstract}

Keywords: crustacean, consumption, cublic health. 


\section{Introdução}

No município de Breves, conhecida como a "Capital do Marajó", Estado do Pará, Brasil, as feiras livres são um dos mais antigos locais de comercialização de alimentos ainda em funcionamento na região marajoara. Também são o de maior volume de venda de pescado, tornando-se por isso uma importante fonte de abastecimento para a comunidade marajoara paraense.

Muitos sobrevivem da pesca de peixe com destaque para os tucunarés (Cichla spp.), poraquê ou peixeelétrico (Electrophorus electricus, Linnaeus, 1766), pescada (Plagioscion squamosissimus, Heckel, 1840), dourada (Brachyplatystoma rousseauxii, Castelnau, 1855), filhote (Brachyplatystoma filamentosum, Lichtenstein, 1819), pirarucu (Arapaima gigas, Schinz, 1822) e tamuatá (Hoplosternum litoralle, Hancock, 1828), além da captura e comercialização do camarão-da-amazônia (Macrobrachium amazonicum Heller, 1862).

Dentre os pescados amazônicos, o camarão-da-Amazônia (M. amazonicum) possui elevada importância nutricional para o povo marajoara. Estudos demonstram que o músculo desta espécie possui até $21 \%$ de proteína e destes, $7 \%$ são de aminoácidos essenciais. Do total de lipídeos, possui elevado teor de ácidos graxos poli-insaturados (47\%) e monoinsaturados (24,0\%) (Montoya-Martinez et al., 2016; Portella, 2009).

Para garantir a segurança alimentar desses consumidores se faz necessário conhecer o perfil das condições higiênico-sanitários da comercialização. Condições inadequadas podem acarretar problemas de saúde pública (surtos), principalmente em se tratando de matéria-prima perecível como o camarão-daamazônia (Alcântara; Kato, 2016). Esta, é influenciada diretamente pela forma de manipulação inadequada dos camarões, etapa onde ocorre boa parte da contaminação.

Uma das principais consequências das inadequações observadas, perante o nosso objeto de estudo, é a possibilidade de alteração no produto, já que o pescado é um alimento que se deteriora com facilidade, devido a seu elevado teor de água, gordura e $\mathrm{pH}$ próximo da neutralidade, favorecendo o desenvolvimento de bactérias prejudiciais à saúde humana (Silva, 2007).

Diante do exposto, objetivou-se traçar o perfil dos vendedores, da comercialização e das condições higiênico-sanitárias durante a venda do M. amazonicum na feira livre da cidade de Breves.

\section{Material e Métodos}

A pesquisa foi conduzida na Feira Livre do município de Breves, estado do Pará, a qual pertence à Mesorregião do Marajó, à Microrregião de furos de Breves e se encontra a $1^{\circ} 40^{\prime} 45^{\prime \prime}$ de latitude sul e $50^{\circ} 29^{\prime} 15^{\prime}$ de longitude W. Gr (Figura 1). A metodologia utilizada no presente trabalho foi de natureza qualitativa, incluindo pesquisa bibliográfica, documental e de campo. Esta última foi realizada no mês de setembro de 2016.

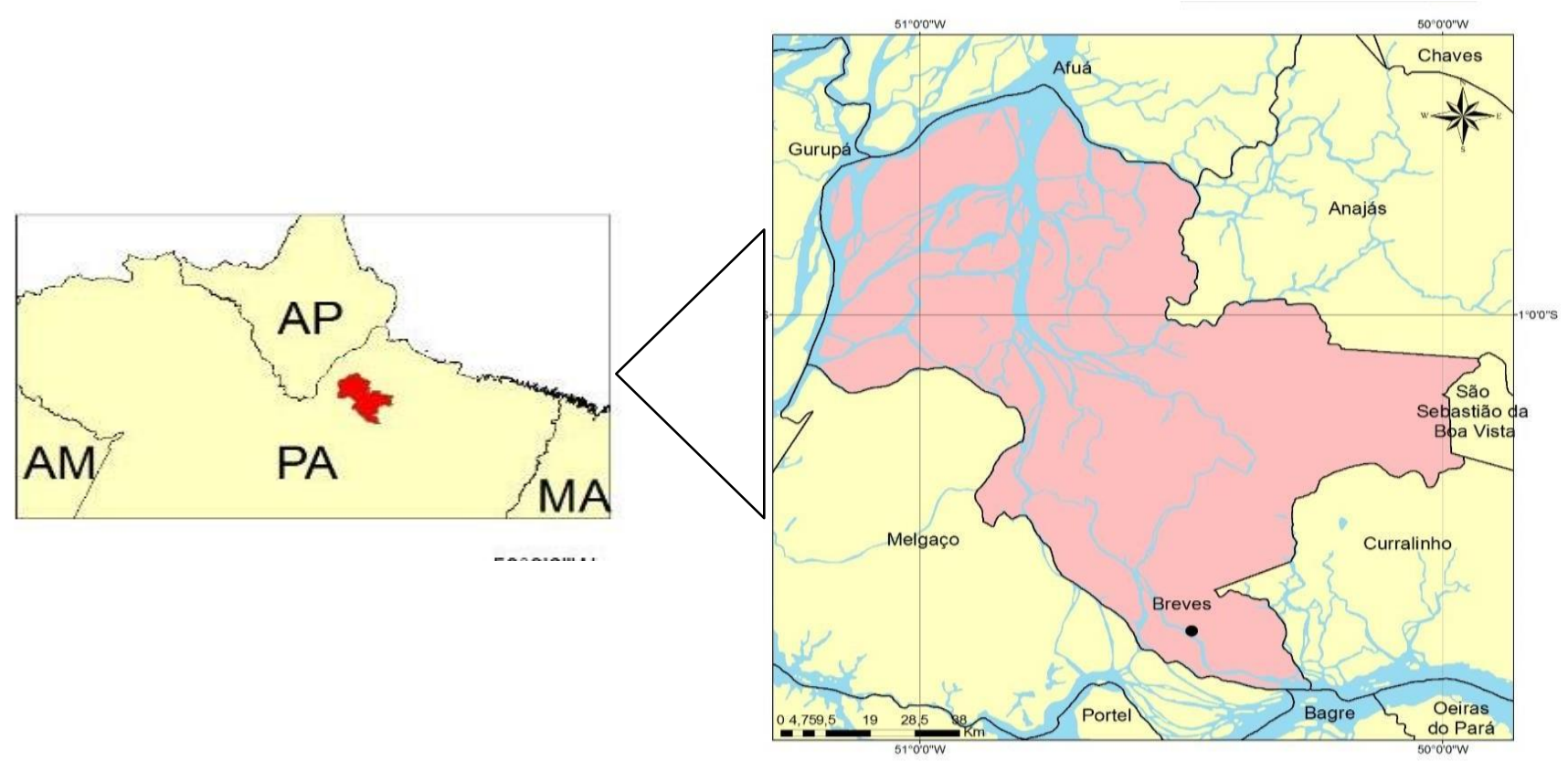

Figura 1. Mapa do município de Breves, Região do Marajó, Estado do Pará. 
Os entrevistados selecionados foram os que ocupavam seus espaços comerciais no período da pesquisa. O período escolhido foi o da manhã pelo fato de haver maior circulação de pessoas e, consequentemente, maior comércio pescados. A maioria das pessoas que frequentam a feira estudada vivem em pequenos povoados, comunidades e vilas madeireiras, às margens dos rios, furos e igarapés que cortam a região. Essas pessoas se deslocam até Breves para adquirir pescados e transportam os mesmo para consumo próprio ou revenda.

Durante todos os dias de visitas à feira foram convidados a participar da pesquisa vendedores que comercializavam camarão-da-amazônia, mas apenas cinco aceitaram fazer parte da pesquisa. Foi então investigado o perfil dos vendedores e da comercialização do camarão através da aplicação uma lista de verificação (check-list).

O roteiro foi elaborado baseado nas exigências contidas no Decreto 45.674 de 29/12/2004, que dispõe sobre o funcionamento das feiras livres no município de São Paulo, e enfatizado nas exigências do Grupo 11 (G11), que estabelece as condições adequadas para comercialização de pescado (São Paulo, 2004) e também com base na da Portaria MS № 326/97, que regulamentam sobre as condições higiênico-sanitárias dos estabelecimentos produtores/industrializadores e as Boas Práticas de Fabricação de alimentos (Brasil, 1997).

Para cada observação positiva foi atribuído créditos às respostas: afirmativas - coluna " $A$ " $=0,5$ e coluna "B" $=0,25$; negativas $=0$. Cada amostra poderia alcançar até 10 créditos. Com a metodologia proposta, quanto maior a quantidade de créditos obtida em cada ponto de venda, maior a quantidade de itens considerados conformes, devido a proximidades com o valor máximo (10,0 créditos) estabelecido para cada ponto de venda. Não foram atribuídos créditos às observações negativas.

Todas as informações foram tabuladas em software Excel for Windows e analisadas estatisticamente através do método descrito por Triola (2005).

Os entrevistados selecionados foram os que ocupavam seus espaços comerciais no período da pesquisa. $\mathrm{O}$ período escolhido foi o da manhã pelo fato de haver maior circulação de pessoas e, consequentemente, maior comércio pescados. A maioria das pessoas que frequentam a feira estudada vivem em pequenos povoados, comunidades e vilas madeireiras, às margens dos rios, furos e igarapés que cortam a região. Essas pessoas se deslocam até Breves para adquirir pescados e transportam os mesmo para consumo próprio ou revenda.

Durante todos os dias de visitas à feira foram convidados a participar da pesquisa vendedores que comercializavam camarão-da-amazônia, mas apenas cinco aceitaram fazer parte da pesquisa. Foi então investigado o perfil dos vendedores e da comercialização do camarão através da aplicação uma lista de verificação (check-list).

O roteiro foi elaborado baseado nas exigências contidas no Decreto 45.674 de 29/12/2004, que dispõe sobre o funcionamento das feiras livres no município de São Paulo, e enfatizado nas exigências do Grupo 11 (G11), que estabelece as condições adequadas para comercialização de pescado (São Paulo, 2004) e também com base na da Portaria MS N $326 / 97$, que regulamentam sobre as condições higiênico-sanitárias dos estabelecimentos produtores/industrializadores e as Boas Práticas de Fabricação de alimentos (Brasil, 1997).

Para cada observação positiva foi atribuído créditos às respostas: afirmativas - coluna "A" $=0,5$ e coluna "B" $=0,25$; negativas $=0$. Cada amostra poderia alcançar até 10 créditos. Com a metodologia proposta, quanto maior a quantidade de créditos obtida em cada ponto de venda, maior a quantidade de itens considerados conformes, devido a proximidades com o valor máximo (10,0 créditos) estabelecido para cada ponto de venda. Não foram atribuídos créditos às observações negativas.

Todas as informações foram tabuladas em software Excel for Windows e analisadas estatisticamente através do método descrito por Triola (2005).

\section{Resultados e Discussão}

\section{Perfil da comercialização do camarão-da-Amazônia}

Na feira livre de Breves/PA, o camarão é comercializado in natura e salgado por $100 \%$ dos entrevistados, com casca e sem casca. No primeiro método de comercialização entende-se como o pescado recémcapturado, submetido ou não a refrigeração e adquirido pelo consumidor ainda em seu estado cru (Brasil, 2010). Entretanto são bastante perecíveis, necessitando de condições sanitárias adequadas desde sua captura, manipulação e comercialização a fim de que seja oferecido ao consumidor um produto seguro e de boa qualidade microbiológica (Abreu et. al., 2008).

$60 \%$ dos comerciantes classificam o camarão em até três classes de tamanho: pequeno, médio e grande. Os camarões considerados pequenos possuem tamanhos entre $2,0 \mathrm{~cm}$ a $5,0 \mathrm{~cm}$, os classificados como médios possuem tamanhos entre $5,0 \mathrm{~cm}$ e $8 \mathrm{~cm}$ e a partir deste são considerados como grades. Valores esses, 
próximos dos encontrados por Lima e Santos (2014) trabalhando com aspectos econômicos e higiênicosanitários da comercialização de camarões de água doce em feiras livres de Macapá e Santana, Estado do Amapá.

Os preços médios de venda do M. amazonicum praticados na feira livre de Breves variam de acordo com o tipo de processamento, tamanho e época do ano (período seco e chuvoso). Em todos os locais de comercialização na feira os preços mostram-se mais baixos no período de seca, devido ao elevado volume de oferta. Os preços neste período variam de 31,50 USD a 47,25 USD e 47,25 USD a 78,75 USD em média para os camarões médios e grandes, respectivamente. Enquanto que no período de cheia os preços médios aumentam bastante e variam de 47,25 USD a 63 USD para camarões pequenos e 63 USD a 110,25 USD para grandes.

A maior parte dos camarões que abastecem o município de Breves é proveniente do rio Ituquara, Jacaré Grande, Boca de Breves, Bagre, Parauare e Afuá. A região do Afuá é a principal responsável pelo abastecimento também nas feiras livres de Macapá e Santana (Lima; Santos, 2014). Todos os entrevistados compraram camarão diretamente dos pescadores nas ilhas e revendem para o consumidor final. Foi mencionado que muitos comerciantes compravam seus produtos por atravessadores, o que ocasionava aumento do preço final para o consumidor.

\section{Perfil higiênico-sanitário durante a comercialização do camarão-da-Amazônia}

As bancas visitadas representam os principais pontos de comercialização do camarão-da-amazônia no município de Breves e através das verificações feitas foram demonstrados os resultados obtidos de cada ponto de comercialização (Tabela 1).

Tabela 1. Número de créditos atribuídos na avaliação de aspectos higiênico-sanitários das bancas de comercialização do camarão-da-amazônia em Breves, estado do Pará.

\begin{tabular}{ccccc}
\hline \multicolumn{5}{c}{ Check-list na venda do Camarão-da-Amazônia } \\
\hline Pontos de venda & Infra-estrutura e organização & Feirante & Pescado & Total de créditos \\
\hline 1 & 0,75 & 0 & 1,0 & 1,75 \\
2 & 0,75 & 0 & 0,5 & 1,25 \\
3 & 0,75 & 0 & 0,25 & 1 \\
4 & 0,5 & 0 & 0,25 & 0,75 \\
5 & 0,5 & 0 & 0,25 & 0,75 \\
\hline
\end{tabular}

O ponto (1) de venda do camarão na feira livre de Breves, apresentou a maior pontuação obtida no estudo, 1,75 créditos, enquanto que os demais pontos de venda $(2,3,4$, e 5), apresentaram as menores pontuações, entre: 0,75 e 1,75 créditos. Contudo, fica visível que em nenhuma das bancas na feira livre visitada os valores obtidos se aproximam do valor máximo permitido de cada ponto de venda ( 10,0 créditos).

\section{Infra-estrutura e organização}

Quanto às instalações físicas do mercado, todos os estabelecimentos visitados estavam em desacordo com a legislação (Brasil, 2004), pois em todos os itens analisados não atenderam às especificações legais: inexistência de pias, instalações sanitárias precárias ou inexistentes, os boxes de manipulação e exposição revestidos em azulejos, sujos, quebrados, em péssimas condições de conservação, de material inadequado, piso com buracos e rachaduras e acumulo de águas servidas.

Resultados desta pesquisa para as instalações físicas do mercado foram diferentes aos encontrados por Barreto et al., (2012) avaliando as condições higiênico-sanitárias do pescado comercializado no município de Cruz das Almas/BA, com relação às condições higiênicas do mercado em todos os boxes os balcões eram de azulejos brancos, contendo pia com torneiras e água encanada, não sendo observada a presença de animais, insetos, banheiros e lixeiras próximas.

Em nenhum dos pontos de venda dos camarões visitados havia sanitário privado para os comerciantes. Contudo, existiam sanitários coletivos citados por 40,0\% da amostra (Figura 2). Apesar disso, vale ressaltar, que as instalações sanitárias da feira livre estudada está em comunicação direta com a área de comercialização de pescado, tornando-se veículo de contaminação e promotor de odor desagradável. 


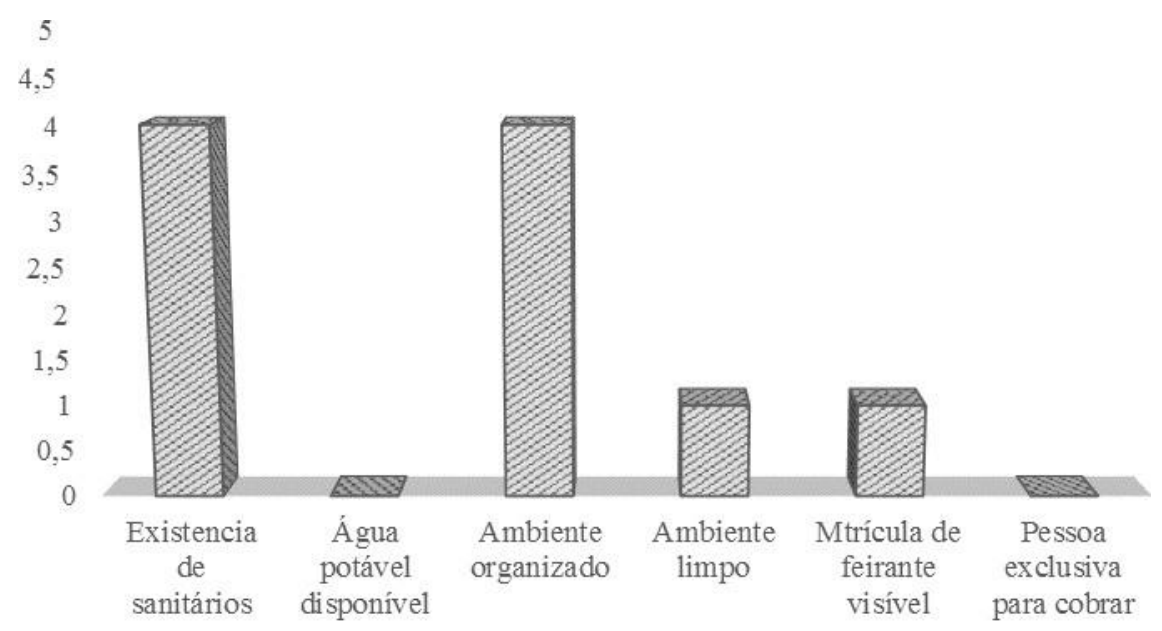

Infra-estrutura e organização da comercialização do Camrão

Figura 2. Adequação das feiras livres aos itens de infra-estrutura e organização durante a comercialização do Camarão-da-Amazônia na feira livre da cidade de Breves, estado do Pará.

Em relação à disponibilidade de água, é recomendado que haja água potável disponível para limpeza de utensílios e mercadoria. Não foi observado essa disponibilidade na feira livre. Tal situação dificulta a higienização dos manipuladores, utensílios e produto. Além disso, utilização de um único recipiente de água para o uso durante a comercialização do Camarão-da-Amazônia é uma prática que possibilita a contaminação cruzada e, portanto, impõe risco à saúde do consumidor.

Outro fator avaliado foi à desorganização e a falta de higiene nas bancas de camarões. Foi verificada a existência de animais domésticos (cachorros e gatos) transitando no espeço de comercialização. Também é importante destacar que os manipuladores de alimentos nesta feira livre são os próprios feirantes, que simultaneamente manipulam alimentos, dinheiro e utensílios. Essas informações também foram relatadas na pesquisa de Macedo et al., (2012) ao analisar as condições higiênico-sanitárias na venda de pescado "in natura" no mercado de peixe no munícipio de Castanhal/PA.

Observou-se em todos os locais amostrados que os feirantes realmente manipularam o camarão e dinheiro ao mesmo tempo. Manipuladores de alimentos possuem um papel importante na disseminação de microrganismos, por isso, as operações neste tipo de comércio também devem atender a um manual de boas práticas de manipulação (Brasil, 2004). Também não foi observada a matrícula dos feirantes em local visível.

\section{Manipuladores}

Com relação aos manipuladores, todos os entrevistados não utilizavam luvas, máscaras ou toucas (EPI) durante a manipulação do camarão. Segundo Moura (2007) os manipuladores devem usar cabelos presos e protegidos por toucas ou outro acessório apropriado para esse fim.

Campos e Paiva (2012), avaliando a condição higiênico-sanitária do pescado comercializado em feira no município de Manaus/AM detectaram que os manipuladores não utilizam uniformes e EPI's como jaleco, gorro, máscara, botas. Assim como, em pesquisa de Pinto et al., (2012) também avaliando as condições higiênico-sanitárias das bancas de comercialização de peixe no mercado do peixe na cidade de Teresina/PI, quanto à proteção dos cabelos, foi observado que alguns feirantes não apresentavam qualquer cuidado com os cabelos, inclusive apresentavam o hábito de coçar a cabeça constantemente e nenhuns dos manipuladores utilizavam luvas descartáveis.

Ressalta-se o perigo representado pela ocorrência de microrganismos em pescado, indicador de contaminação oriunda de fossas nasais, boca e pele de manipuladores, bem como de sanitização inadequada de utensílios utilizados na manipulação o que evidencia a importância do controle higiênico-sanitário em estabelecimentos industriais e comerciais, quanto ao pessoal, utensílios e superfícies que entram em contato com o produto (Evangelista, 2001). Segundo a RDC n $12 / 2001$, que trata do regulamento técnico sobre padrões microbiológicos em alimentos, os possíveis microrganismos patogênicos em pescados frescos como o camarão são Staphylococcus aureus (principalmente por causa da manipulação) e Salmonella spp. (Brasil, 2001). 


\section{Camarão}

Acta of Fisheries and Aquatic Resources

Foram encontrados na feira a venda do camarão fresco inteiro, fresco descabeçado e salgado inteiro. Nos boxes entrevistados, o camarão fresco foi encontrado em basquetas de plástico (PVC) com gelo, enquanto que o salgado somente em basquetas.

Observou-se que em todos os boxes havia contato direto dos consumidores com o produto e que os camarões ficavam expostos de maneira inadequada, conforme preconiza o Regulamento Técnico de Identidade e Qualidade (RTIQ) para camarão fresco (Brasil, 2010). Evidenciando assim a exposição do produto, sem nenhuma proteção contra poeira e insetos, aumentando a chance de contaminação microbiana e da deterioração acelerada do pescado (Figura 3).

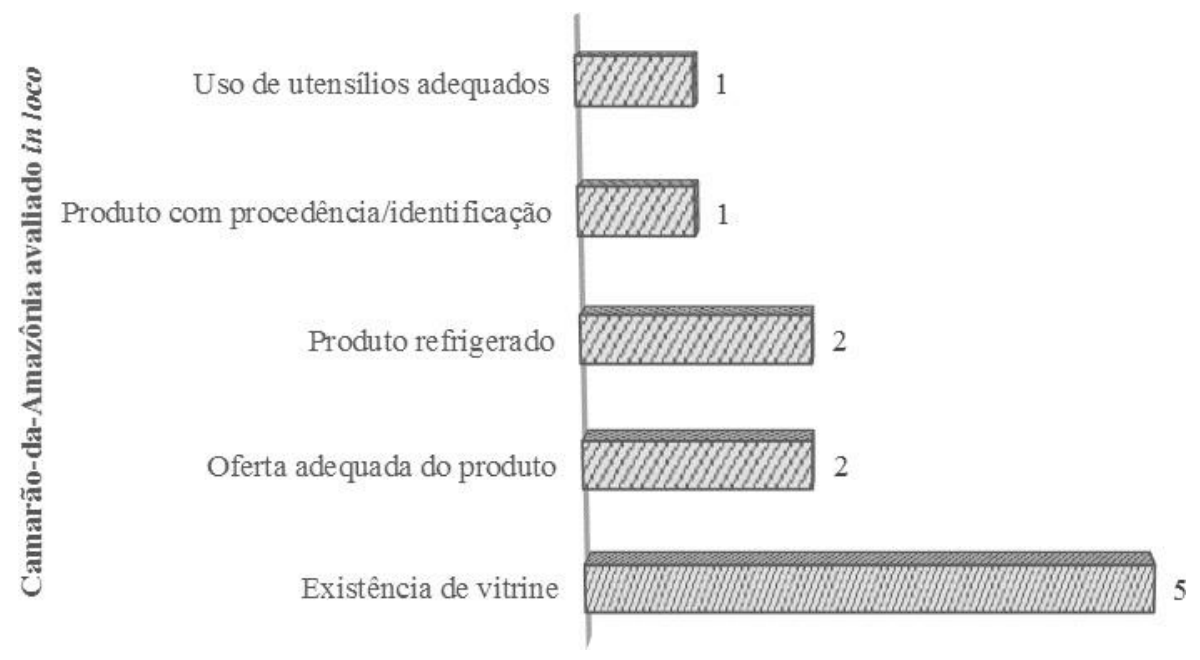

Figura 3. Itens relacionados ao camarão avaliado in loco na feira livre da cidade de Breves. Estado do Pará

Lino et al., (2009) avaliando as condições higiênico-sanitárias dos estabelecimentos de comercialização de carnes nos mercados públicos de Jaboatão dos Guararapes/PE, constatou-se que $119(99,17 \%)$ dos comerciantes que participaram do estudo deixavam seu produto à temperatura ambiente, dos quais 45 (37,5\%) utilizavam bandejas, $42(35 \%)$ em ganchos e $32(26,66 \%)$ no próprio balcão, desta forma, apenas 1 $(0,83 \%)$ utilizava freezer expositor.

Muitos dos camarões avaliados se encontravam em bandejas e expostos à poeira e insetos presentes no ambiente. Utensílios e equipamentos são considerados veículos de contaminação em alimentos, quando higienizados apressadamente ou de maneira inadequada (Gomes et al., 2012).

Percebe-se nos pontos de estudo apresentou não conformidades com requisitos preconizados pela legislação. Portanto, há uma necessidade de reestruturação da feira, bem como, promover a capacitação e conscientização dos manipuladores. Projeto simples podem ser executados para repassar informações básicas a respeito das condições corretas de manipulação e comercialização de camarões de água doce e de pescados em geral.

\section{Referências}

Abreu, M. G.; Freitas, M. Q.; Jesus, E. F. O.; São Clemente, S. C.; Franco, R. M. \& Borges, A. (2008) Caracterização sensorial e análise bacteriológica do peixe-sapo (Lophius gastrophysus) refrigerado e irradiado. Revista Ciência Rural 38(2): 498-503.

Alcântara, G. L. C. \& Kato, H. C. A. (2016) Boas práticas de manipulação na comercialização do camarão fresco em feiras livres de Belém, PA. Journal of bioenergy and food science 3(3): 139-148.

Barreto, N. S. E.; Moura, F. C. M.; Teixeira, J. A.; Assim, D. A. \& Miranda, P. C. (2012) Avaliação das condições higiênico-sanitárias do pescado comercializado no município de Cruz das Almas, Bahia. Revista Caatinga, Mossoró 25(3): 86-95.

Brasil. Ministério da Agricultura, Pecuária e Abastecimento. (1952) Riispoa - Regulamento da Inspeção Industrial e Sanitária de Produtos de Origem Animal. Decreto n ${ }^{\circ} 30691$, de 29/03/52. Brasília/DF: 
Ministério da Agricultura, Pecuária e Abastecimento.

Brasil. Portaria $\mathrm{n}^{\circ}$ 456, de 10 de Setembro de (2010). Regulamento Técnico de Identidade e Qualidade para Camarão Fresco. Ministério da Agricultura, Pecuária e Abastecimento. Secretaria de Defesa Agropecuária.

Brasil. Resolução RDC n⿳ำ 12, de 2 de janeiro de (2001). Ministério da Saúde, Agência Nacional da Vigilância Sanitária.

Brasil. Resolução RDC n 216 de 15 de Setembro de (2004). Dispõe sobre Regulamento Técnico de Boas Práticas para Serviços de Alimentação. Ministério da Agricultura, Pecuária e Abastecimento.

Evangelista, J. (2001) Tecnologia de Alimentos. 2ed. São Paulo: Atheneu, p.664.

Lima, J.F. \& Santos, T.S. (2014) Aspectos econômicos e higiênico-sanitários da comercialização de camarões de água doce em feiras livres de Macapá e Santana, Estado do Amapá. Biota Amazônia 4(1): 18.

Lino, G. C.; Pacheco, M. S.; Rolim, M. B. Q.; Paiva, J. N. \& Moura, A. P. B. L. (2009) Condições higiênicosanitárias dos estabelecimentos de comercialização de carnes nos Mercados Públicos de Jaboatão dos Guararapes, PE. Revista Medicina Veterinária, Recife 3(4): 1-6.

Macedo, A. G.; Silva, F. L.; Sampaio, L. O.; Ribeiro, S. A. (2012) Análise das condições higiênico-sanitárias na venda de pescado "in natura" no mercado de peixe no município de Castanhal-Pará. In: Anais Congresso Internacional de Tecnologias para o Meio Ambiente, 2012, Caxias do Sul. Rio Grande do Sul: FIEMA Brasil, p. 1-8. Acessado em: http://bit.ly/1tYRot1.

Montoya-Martínez, C.; Nolasco-Soria, H.; Carrillo-Farnés, O.; Civera-Cerecedo, R.; Álvarez-González, C. \& Vega-Villasante, F. (2016) Chemical score of different protein sources to four Macrobrachium species. Latin American Journal of Aquatic Research 44(4): 835-844.

Moura, H.F. (2007) A Qualidade dos Alimentos no Contexto da Política de Segurança Alimentar: estudo de Caso numa Feira Livre Tradicional de Fortaleza. 2007. 114p Tese (Mestrado em Planejamento e Políticas Públicas) - Universidade Estadual do Ceará, Fortaleza, 2007.

Pinto, L. I. F.; Borges, J. M.; Abreu, M. M.; Castro, A. S.; Alencar, G. R. R.; Feitosa, R. G. N. (2012) Avaliação das condições higiênico-sanitárias das bancas de comercialização de peixe no mercado do peixe na cidade de Teresina-PI. In: Congresso Norte Nordeste de Pesquisa e Inovação, Palmas.

Portella, C. G. (2009) Tecnologia pós-despesca dos camarões de água doce Macrobrachium rosenbergii e Macrobrachium amazonicum Tecnologia pós-despesca dos camarões de água doce Macrobrachium rosenbergii e Macrobrachium amazonicum. [s.1.] Universidade Estadual Paulista.

Silva, C. (2007) Código de boas práticas: boas práticas de higiene e boas práticas de fabrico. Portal de saúde pública. Publicação eletrônica. Disponível em: http://bit.ly/1prWuYu.

Triola, M. F. (2005) Introdução à Estatística. 9ª ed. Rio de Janeiro: LTC Editora. 